\title{
Household food insecurity is independently associated with poor utilization of maternal healthcare services in Bangladesh
}

\author{
Ghose Bishwajit $^{a \star}$ and Sanni Yaya ${ }^{b}$ \\ ${ }^{a}$ School of Medicine and Health Management, Tongji Medical College, Huazhong University of Science \\ and Technology, Wuhan, China; ${ }^{b}$ School of International Development and Global Studies, University of \\ Ottawa, Ottawa, ON K1N 6N5, Canada \\ *brammaputram@gmail.com
}

\section{OPEN ACCESS}

Citation: Bishwajit G and Yaya S. 2017 Household food insecurity is independently associated with poor utilization of maternal healthcare services in Bangladesh. FACETS 2: 969-983. doi: 0.1139 / facets-2017-00 18

Editor: Debra Clendinneng

Received: February 23, 2017

Accepted: July 31, 2017

Published: December 4, 2017

Copyright: (C) 2017 Bishwajit and Yaya. This work is licensed under a Creative Commons Attribution 4.0 International License (CC BY 4.0), which permits unrestricted use, distribution, and reproduction in any medium, provided the original author(s) and source are credited.

Published by: Canadian Science Publishing

\section{Abstract}

Introduction: Food insecurity at the individual level has been shown to be associated with the adoption of risky behavior and poor healthcare-seeking behavior. However, the impact of household food insecurity (HFI) on the utilization of maternal healthcare services (MHS) remains unexplored. In this study, we aimed to investigate whether or not household food insecurity was associated with non/inadequate utilization of MHS.

Methods: Participants consisted of 3562 mothers aged between 15 and 49 years and with at least one child. The outcome variable was the utilization of MHS, e.g., institutional delivery, attendance ante-, and pre-natal visits. The explanatory variables included various sociodemographic factors (e.g., age, residence, education, wealth) apart from HFI. HFI was measured using the Household Food Insecurity Access Scale (HFIAS).

Result: The prevalence of non- and under-utilization of MHS was 5.3 and 36.5, respectively. In the multivariate analysis, HFI, wealth index, and educational level were independently associated with MHS status. The odds of non- and under-utilization of MHS were 3.467 (CI = 1.058-11.354) and 4.104 (CI = 1.794-9.388) times higher, respectively, among women from households reporting severe food insecurity.

Conclusion: Severe HFI was significantly associated with both under- and non-utilization of MHS. Interventions programs that address HFI and the empowerment of women can potentially contribute to an increased utilization of MHS.

Key words: antenatal care, Demographic and Health Survey, food insecurity, maternal healthcare services

\section{Introduction}

The key role that maternal healthcare services (MHS) plays in reducing maternal mortality rate (MMR) has been substantiated by researchers both in developed and developing country contexts (Cleland et al. 2006; Dowswell et al. 2010; Adegoke et al. 2012; Finlayson and Downe 2013). However, developing regions, especially South Asia and sub-Saharan Africa, are lagging behind the rest of the world in their capacity to put this knowledge into practice (Bishwajit 2015). Initiatives 
led by the maternal health-related millennium development goal (MDG) 5 initiative saw a $34 \%$ decline in MMR since 1990 (Dynes et al. 2013). Despite that, MMR in low- and middle-income countries (LMICs) remains alarmingly high and reveals a continuing disparity in the provision and utilization of MHS in these countries (Kassebaum et al. 2014). A systematic review found that LMICs together account for almost all of the total maternal mortalities (99\%) (Hogan et al. 2010), with South Asian countries representing about one third of the global total (Zanconato et al. 2006). Globally, about $97 \%$ of the unsafe abortions occur in LMICs and this contributes to about $15 \%$ of total maternal mortality (Baer et al. 2015).

The difference in the burden of MMR between high-income countries (HICs) and LMICs coincides with that of the utilization of MHS. In developed countries about $98 \%$ of women receive adequate antenatal care (ANC) services and skilled birth attendants supervise $94 \%$ of the deliveries (Zanconato et al. 2006), whereas in LMICs about half of all women remain deprived of basic ANC (Finlayson and Downe 2013). This strikingly high divide is generally attributed to poor healthcare infrastructure, health illiteracy, underutilization of maternal health care and family planning, and inadequate access to obstetric care (Lewis 2003; Cleland et al. 2006; Zanconato et al. 2006; Nour 2008), all of which are widely prevalent across south Asian countries including Bangladesh.

Bangladesh has made appreciable progress in its pursuit of reducing maternal and under-five child mortality rates. Despite that, the mortality rates continue to be noticeably high when compared with high-income countries. Generally, this discrimination is attributed to the underutilization of MHS, and financial and infrastructural barriers to access to quality care in the current socioeconomic context. For instance, researchers mentioned that although the lack of affordability of healthcare is a major problem, the role of women empowerment and decision-making power for proper utilization of MHS is also a key issue in the country (Yaya et al. 2017). MHS is provisioned mainly through public and private establishments, as well as community healthcare centers, with traditional care providers being more prevalent in the rural areas. The costs of care vary widely, with the private hospitals being the most expensive and hence unaffordable for the majority of the population. To overcome this barrier, the government has taken initiatives to provide service through community healthcare centers that are widely distributed throughout the country.

Previous studies have reported that in Bangladesh, the majority of maternal deaths occur during the time between the third trimester and the first week following delivery (Winch et al. 2005). These deaths could be prevented to a considerable extent by proper information and guidance for maternal health-seeking behavior disseminated through prenatal/maternal education programs (Moran et al. 2007). However, designing such programs will require massive efforts, including a great amount of financing and research work to develop a deep understanding of the factors that influence maternal healthcare-seeking behavior (HSB). This can be a crucial step towards evidencebased health policy making that targets better infant and maternal health outcomes (Darmstadt et al. 2005).

Maternal HSB, like any health-related behavior, is by nature a complex psychological construct that is shaped at individual, familial, and social levels by various demographic, economic, and sociocultural forces. In the domain of behavioral psychology, the stress agents (stressors) hold a central position as they have been shown to affect almost all aspects of psychosocial life via behavioral pathways, e.g., mood, lifestyle factors, perception of health, and well-being (Moran et al. 2007). Food insecurity, although generally thought of as an outcome of financial or resource constraints (Baer et al. 2015), is also found to be affected by behavioral aspects (Timmer 2012). Previous studies have outlined the impact of proximate socioeconomic stressors such as poverty and food vulnerability on HSB (Sundari Ravindran 2014; Young et al. 2014). It is, therefore, assumable that women who face 
hardships to secure food will face the trade-off between nutrition and medical care that will eventually lead to non- or under-utilization of maternal healthcare. A previous study on American households reported that housing instability and food insecurity were associated with poor access to healthcare (Bhargava and Lee 2016). Based on current literature, we hypothesized that household food insecurity (HFI) would be associated with suboptimal utilization of MHS. Given the high rate of HFI and maternal and infant mortality, the findings are expected to be of crucial importance for public health policy making in the country.

\section{Methods}

\section{Data source}

We used cross-sectional datasets extracted from the sixth round of the Bangladesh Demographic and Health Survey (BDHS). BDHS is a nationally representative survey that collects information on various demographic, socioeconomic, and health indicators among adult men (15-59 years), women (15-49 years), and infants (children under 5 years). The survey was conducted by the National Institute of Population Research and Training (NIPORT), a renowned health research organization in Bangladesh (NIPORT et al. 2013). The survey is a part of the International Demographic and Health Survey program known as the MEASURE Demographic and Health Survey (DHS), which is currently active in 90 countries, and was conducted under the auspices of the United States Agency for International Development (USAID) and the technical assistance of ICF International in Calverton, Maryland, USA. Details regarding the sampling and data collection methods are available from the publication by NIPORT (NIPORT et al. 2013).

\section{Variables}

MHS utilization status was the outcome variable in this study. The independent variable of primary interest was HFI.

\section{Food insecurity}

DHS utilizes a retrospective method called the Household Food Insecurity Access Scale (HFIAS) to measure the prevalence and degree of HFI. The scoring system is based on responses to following yes or no questions: (1) had three square meals in the past 12 months, (2) skipped entire meals in the past 12 months, (3) ate less food in the past 12 months, (4) ate wheat or rice in the past 12 months, and (5) asked for food from relatives or neighbors in the past 12 months. Scores range from 0 to 15 , with 0 representing the most secure and 15 the least secure. This scaling method was originally developed by the USAID-funded Food and Nutrition Technical Assistance (FANTA) project. For this study, HFI status was dummy coded into four groups in the following manner: $0=$ Secure, 1 to $5=$ moderately food secure, 6 to $10=$ insecure, and 11 to $15=$ severely insecure. The HFIAS scale was previously validated for Bangladesh (Swindale and Bilinsky 2006).

\section{MHS}

A literature review assisted in the selection of proximate socioeconomic, demographic, and individual level factors for MHS.

Maternal healthcare utilization status is usually measured by two composite elements based on the services: (1) childbirth (place of delivery) and (2) before and after childbirth (ANC and postnatal care (PNC) visits) (Baer et al. 2015). Based on these two elements, MHS utilization status was categorised into three groups. Group 1 consisted of those who received service neither at childbirth nor ANC and PNC services (at least one ANC and PNC attendance), group 2 consisted of those who received either of the two, and group 3 consisted of those who received both types of services. 
First, a participant was considered as not using MHS provided the place of delivery was the home; this was dichotomized as the home (whether of the participant or relatives) versus a health institution (i.e., medical college hospital, upazila health complex, maternal and child welfare center, or health and family welfare centre). Second, a participant was considered as not using MHS before or after delivery unless she had at least one ANC and one PNC visit.

To select the potentially relevant covariates in the context of maternal health behavior, an extensive literature review was conducted focusing on the three most proximate themes: demographic status, socioeconomic status, and media use. As per availability in the dataset, the following were included in the analysis: age, region, residency, religion, education level of the participant and her husband, working status of the participant, type of employment of the husband, household wealth index, household having electricity, membership in any microcredit institution, autonomy in decisionmaking (being able to decide how spend personal income and on own health care), and media use (newspaper, TV, and radio).

Age

Age was trichotomized into three groups: 11-24 years, 25-34 years, and 35-49 years. Participants in all seven administrative regions including Barisal, Chittagong, Dhaka, Khulna, Rajshahi, Rangpur, and Sylhet were included in this study. Place of residency was categorized as rural or urban. Religion was categorized into Islam (the dominant faith in the country), and others (Hinduism, Buddhism, and Christianity). The working status of participants was categorized as employed or unemployed.

\section{Educational status}

Growing evidence suggests that educational status is one of the most direct indicators of population health and health-related behavior. The educational statuses of both the participant and their husband were categorized into four groups based on the total number of years of formal education received: $0=$ nil, $1=$ primary ( $1-5$ years $), 2=$ secondary $(6-10$ years $)$, and $3=$ higher $(>10$ years $)$.

\section{Occupation}

Type of occupation was categorized as follows: (1) farming = farmer, agricultural worker, fisherman, poultry farmer, and cattle raising; (2) blue-collar jobs = carpenter, mason, driver, construction worker, rickshaw puller, brick breaking, and road building; (3) white-collar jobs = businessman, physician, lawyer, accountant, teacher, and government service holder; (4) others = student, religious leader, retired, and unemployed.

\section{Wealth index}

Household wealth status was categorized as follows: poor, poorest, middle, rich, and richest. Households were ranked by the score they were assigned based on the possession of durable goods (e.g., TV, radio, refrigerator, and construction material). Categorization was performed by dividing the household wealth scores into quintiles. The richest households were those in the highest quintile, and poorest were in the lowest quintile. The procedures for calculating wealth status in DHS studies have been explained in previous studies (Yaya et al. 2017).

\section{Microcredit institution membership}

Microfinance programs have been shown to have a positive impact on women's empowerment and to promote overall socioeconomic status. Mothers who are involved with such programs are expected to have better economic solvency and therefore better adherence to maternal care protocols. Participants of this study were categorized according to their membership with any of the four microcredit institutions (Association for Social Advancement (ASA), Bangladesh Rural Advancement Committee 
(BRAC), Bangladesh Rural Development Board (BRDB), and Grameen Bank) as follows: $0=$ no membership; 1 = membership with at least one institution or with multiple institutions.

Media use

Utilization of paper and electronic media has been shown to promote health awareness among adults. In this study, media use status was measured by the habit of watching TV, listening to radio, and reading newspaper as follows: $0=$ not using at all; $1=$ using sometimes/regularly.

\section{Statistical analysis}

The initial dataset was checked for cases that fulfilled all of the inclusion criteria, and data were entered into a separate working file for analysis. To ensure data accuracy the new dataset was rechecked for outliers and missing values by two independent authors. In total, 3562 cases were retained in the final dataset.

The dependent variable was trichotomized into three easily distinguishable groups based on the utilization of services of the two different types as described earlier (i.e., during delivery, and before and after delivery). The three groups (group 1,2, and 3) indicated non-, under-, and full utilization of MHS.

First, a frequency table was created to describe the baseline characteristics of the study participants. Following that, $\chi^{2}$ bivariate analysis was performed to detect the variables that significantly contributed to MHS utilization status. The variables that showed statistical significance $($ at $p<0.25)$ in bivariate analysis were selected for regression analysis. A multinomial regression model was used to determine the association between HFI and MHS. The results of the regression analysis were reported in terms of odds ratios and $95 \%$ confidence intervals. The $p$-values were only considered statistically significant when $<0.05$. All analyses were performed using SPSS version 21.0 for MAC (SPSS Inc., Chicago, Illinois, USA).

\section{Ethical clearance}

Informed consent was obtained from all participants before each interview. This study is not subject to further ethical approval because the data are secondary and available in the public domain in an anonymized form.

\section{Results}

\section{Sample characteristics}

Table 1 shows the baseline characteristics of the study population $(n=3652)$. About three fifths of the participants were of rural origin, and participation was highest in the Chittagong district. Most of the participants belonged to the age group of 15 to 24 years. About $88.7 \%$ of them were Muslim, which is close to the proportion observed at the country level ( 89.5). Almost half of the women completed secondary school and $15 \%$ achieved above secondary level. The overall literacy rate was higher among women $(89.3 \%)$ than among their husbands $(82.1 \%)$. However, the percentage of participants with qualifications above the secondary school level was higher among the husbands. One fourth of the study participants were microcredit borrowers. However, nearly $90 \%$ of the women were nonworking mothers. The majority of participants belonged to highest wealth quintile (32\%), which may be because in about one third of the cases, the husbands were white-collar employees in the most well-paid job categories. Only 1 in 10 women had the ability to make health decisions independently. The percentage was even lower (8.6\%) for decisions about spending personal income. The majority of the women were from households with good (72.2\%) to moderately good (21.6\%) level of food 
Table 1. Background characteristics of the study participants.

\begin{tabular}{|c|c|c|}
\hline Variables & Frequency & Percentage (\%) \\
\hline \multicolumn{3}{|l|}{ Age } \\
\hline $15-24$ & 1792 & 50.3 \\
\hline $25-34$ & 149 & 40.2 \\
\hline $35-49$ & 271 & 7.6 \\
\hline \multicolumn{3}{|l|}{ Residency } \\
\hline Urban & 1458 & 40.9 \\
\hline Rural & 2104 & 59.1 \\
\hline \multicolumn{3}{|l|}{ Region } \\
\hline Barisal & 393 & 11 \\
\hline Chittagong & 620 & 17.4 \\
\hline Dhaka & 590 & 16.6 \\
\hline Khulna & 530 & 14.9 \\
\hline Rajshahi & 470 & 13.2 \\
\hline Rangpur & 488 & 13.7 \\
\hline Sylhet & 471 & 13.2 \\
\hline \multicolumn{3}{|l|}{ Religion } \\
\hline Islam & 3161 & 88.7 \\
\hline Others & 401 & 11.3 \\
\hline \multicolumn{3}{|c|}{ Education level of the participant } \\
\hline Nil & 381 & 10.7 \\
\hline Primary & 867 & 24.3 \\
\hline Secondary & 1777 & 49.9 \\
\hline Higher & 537 & 15.1 \\
\hline \multicolumn{3}{|c|}{ Education level of the husband } \\
\hline Nil & 636 & 17.9 \\
\hline Primary & 899 & 25.2 \\
\hline Secondary & 1230 & 34.5 \\
\hline Higher & 797 & 22.4 \\
\hline \multicolumn{3}{|c|}{ Microcredit borrower } \\
\hline Yes & 907 & 25.5 \\
\hline No & 2269 & 63.7 \\
\hline \multicolumn{3}{|c|}{ Wealth index } \\
\hline Poorest & 460 & 12.9 \\
\hline Poorer & 507 & 14.2 \\
\hline Middle & 633 & 17.8 \\
\hline Richer & 822 & 23.1 \\
\hline
\end{tabular}


Table 1. (concluded)

\begin{tabular}{|c|c|c|}
\hline Variables & Frequency & Percentage (\%) \\
\hline Richest & 1140 & 32 \\
\hline \multicolumn{3}{|c|}{ Participant currently working } \\
\hline Yes & 369 & 10.4 \\
\hline No & 3193 & 89.6 \\
\hline \multicolumn{3}{|c|}{ Husband's occupation } \\
\hline Farming & 427 & 12 \\
\hline Blue-collar jobs & 987 & 27.7 \\
\hline White-collar jobs & 1290 & 36.2 \\
\hline Others & 858 & 24.1 \\
\hline \multicolumn{3}{|l|}{ Food security level } \\
\hline Severely insecure & 35 & 1 \\
\hline Insecure & 187 & 5.2 \\
\hline Moderately secure & 768 & 21.6 \\
\hline Secure & 2572 & 72.2 \\
\hline \multicolumn{3}{|c|}{ Household has electricity } \\
\hline Yes & 2655 & 74.5 \\
\hline No & 907 & 25.5 \\
\hline \multicolumn{3}{|c|}{ Has a say in own health care decisions } \\
\hline Yes & 419 & 11.8 \\
\hline No & 3143 & 88.2 \\
\hline \multicolumn{3}{|c|}{ Can decide on spending personal income } \\
\hline Yes & 308 & 8.6 \\
\hline No & 3254 & 91.4 \\
\hline \multicolumn{3}{|l|}{ Reads newspaper } \\
\hline Yes & 931 & 26.1 \\
\hline No & 2631 & 73.9 \\
\hline \multicolumn{3}{|l|}{ Watches TV } \\
\hline Yes & 2543 & 28.6 \\
\hline No & 1019 & 71.4 \\
\hline \multicolumn{3}{|l|}{ Listens to radio } \\
\hline Yes & 367 & 10.3 \\
\hline No & 3195 & 89.7 \\
\hline
\end{tabular}

security. Women from $1 \%$ of the households faced severe food insecurity. About one fourth of the women reported having the habit of reading newspapers. Although three fourths of women reported living in a household with access to electricity, the rate of utilization of electronic media was quite low (28.6 for television and 10.3 for radio). 


\section{Factors influencing the utilization of MHS (bivariate association)}

Based on the Pearson's $\chi^{2}$-test result (shown in Table 2), the following variables were found to be significantly associated with MHS utilization status: residency, education level of the participant and her husband, occupation category of the husband, household wealth index, microcredit institution membership, and level of food security. Age, religion, and regional variation showed no association.

Participants of rural origin had a lower likelihood of utilizing MHS compared with their urban counterparts. Women whose husbands were engaged in white-collar jobs were more likely to utilize MHS. Women with no education had higher probability of underutilization of MHS and had almost sevenfold the risk of non-utilization compared with the most educated. Women belonging to highest wealth group index had notably higher maternal service attendance than the poorest group (10.1 vs. 36.8). The poor and poorer groups combined accounted for $56 \%$ of the women who didn't receive any service.

Household wealth index and level of food security were significantly associated with the utilization of MHS of both types. For husbands, the type of occupation and level of education showed significant associations.

Quite unexpectedly, working status and decision-making ability were not found to be significantly associated with MHS uptake. Seven predictors were found to be significant at $p<0.05$ and were entered into the multivariate analysis.

\section{Multivariate analysis}

Of the seven variables entered into the multivariate analysis, the following three were found to be significantly associated with non- and under-utilization of MHS: educational level of the participant, household wealth index, and household food security level. The impacts of the husband's characteristics (educational level and type of occupation), media utilization (television, radio, and newspaper), and women's decision-making status were found to be insignificant after adjusting for confounding factors.

The level of education of the participant was found to be significantly associated with both non- and under-utilization of MHS (Table 3). The odds of not utilizing any service were 10 times higher for women with no formal education compared with their most educated counterparts. Women who completed primary education had 6.80 and 1.43 higher odds of non- and under-utilization of MHS, respectively. However, for women with secondary level qualification, educational status showed no significant impact on their service utilization status.

Results also revealed that the poorer the household, the higher the likelihood of non-utilization of MHS. Compared with the richest, the odds ratios of non-utilization of MHS were 7.814 $(\mathrm{CI}=3.21-18.98)$ for the poorer and $9.28(\mathrm{CI}=3.60-23.90)$ for the poorest.

The likelihood of MHS utilization decreased with the lowering of household food security level. Women from most food insecure households were four times more unlikely to utilize MHS of any form and 3.5 times more likely to underutilize MHS compared with those from food secure households. However, being moderately food secure showed no significant impact on MHS underutilization status.

\section{Discussion}

This study documents the factors influencing the non- and under-utilization of MHS in Bangladesh. To our knowledge, this is first study to establish an association between HFI and 
Table 2. $\chi^{2}$ bivariate analysis results for the association between basic demographic and socioeconomic variables with the utilization status of maternal healthcare services.

\begin{tabular}{|c|c|c|c|c|}
\hline Variables & $\begin{array}{l}\text { Non-utilization }(\%) \\
\quad(n=189,5.3 \%)\end{array}$ & $\begin{array}{l}\text { Underutilization (\%) } \\
(n=1234,34.6 \%)\end{array}$ & $\begin{array}{l}\text { Full utilization (\%) } \\
(n=2139,60.1 \%)\end{array}$ & $p$ \\
\hline Age & & & & 0.247 \\
\hline $15-24$ & 55 & 50 & 50.1 & \\
\hline $25-34$ & 34.9 & 42.9 & 42.2 & \\
\hline $35-49$ & 10.1 & 7.1 & 7.8 & \\
\hline Residency & & & & $<0.001^{a}$ \\
\hline Urban & 21.1 & 37.9 & 44.4 & \\
\hline Rural & 78.8 & 62.1 & 55.6 & \\
\hline Region & & & & 0.169 \\
\hline Barisal & 9 & 10.5 & 11.5 & \\
\hline Chittagong & 19 & 17.6 & 17.2 & \\
\hline Dhaka & 19 & 17.6 & 15.8 & \\
\hline Khulna & 13.8 & 16 & 14.4 & \\
\hline Rajshahi & 11.6 & 12 & 14 & \\
\hline Rangpur & 10.1 & 12.6 & 14.6 & \\
\hline Sylhet & 17.5 & 13.8 & 12.5 & \\
\hline Religion & & & & 0.059 \\
\hline Islam & 93.1 & 89.5 & 87.9 & \\
\hline Others & 6.9 & 10.5 & 12.1 & \\
\hline $\begin{array}{l}\text { Education level of the } \\
\text { participant }\end{array}$ & & & & $<0.001^{a}$ \\
\hline Nil & 28 & 13.5 & 7.6 & \\
\hline Primary & 40.2 & 28.4 & 20.6 & \\
\hline Secondary & 30.2 & 45.3 & 54.3 & \\
\hline Higher & 1.6 & 12.9 & 17.5 & \\
\hline $\begin{array}{l}\text { Education level of the } \\
\text { husband }\end{array}$ & & & & $<0.001^{a}$ \\
\hline Nil & 37 & 21.6 & 14 & \\
\hline Primary & 36 & 26.6 & 23.5 & \\
\hline Secondary & 21.2 & 32.4 & 36.9 & \\
\hline Higher & 5.8 & 19.4 & 25.5 & \\
\hline $\begin{array}{l}\text { Microcredit institution } \\
\text { membership }\end{array}$ & & & & $0.033^{a}$ \\
\hline Yes & 29.1 & 25.1 & 21.6 & \\
\hline No & 70.9 & 74.9 & 78.4 & \\
\hline Wealth index & & & & $<0.001^{a}$ \\
\hline Poorest & 31.7 & 14.8 & 10.1 & \\
\hline Poorer & 24.9 & 16 & 12.3 & \\
\hline
\end{tabular}


Table 2. (concluded)

\begin{tabular}{|c|c|c|c|c|}
\hline Variables & $\begin{array}{l}\text { Non-utilization }(\%) \\
\quad(n=189,5.3 \%)\end{array}$ & $\begin{array}{l}\text { Underutilization (\%) } \\
(n=1234,34.6 \%)\end{array}$ & $\begin{array}{l}\text { Full utilization (\%) } \\
(n=2139,60.1 \%)\end{array}$ & $p$ \\
\hline Middle & 21.2 & 18.9 & 16.8 & \\
\hline Richer & 18 & 22.4 & 23.9 & \\
\hline Richest & 4.2 & 27.9 & 36.8 & \\
\hline Currently working & & & & 0.938 \\
\hline Yes & 11.1 & 10.4 & 10.3 & \\
\hline No & 88.9 & 89.6 & 89.7 & \\
\hline Food security & & & & $<0.0001^{a}$ \\
\hline Severely insecure & 2.6 & 1.8 & .4 & \\
\hline Insecure & 14.8 & 6.2 & 3.8 & \\
\hline Moderately secure & 29.1 & 25.2 & 18.8 & \\
\hline Secure & 53.4 & 66.8 & 77 & \\
\hline Household has electricity & & & & 0.139 \\
\hline Yes & 45.5 & 60.8 & 67 & \\
\hline No & 55.5 & 39.2 & 33 & \\
\hline $\begin{array}{l}\text { Has a say in own health } \\
\text { care decisions }\end{array}$ & & & & 0.067 \\
\hline Yes & 13.2 & 10 & 12.6 & \\
\hline No & 86.8 & 90 & 87.4 & \\
\hline $\begin{array}{l}\text { Can decide on spending } \\
\text { personal income }\end{array}$ & & & & 0.494 \\
\hline Yes & 10.6 & 8.1 & 8.8 & \\
\hline No & 89.4 & 91.9 & 91.2 & \\
\hline Husband's occupation & & & & $<0.001^{a}$ \\
\hline Farming & 19.6 & 13.6 & 10.4 & \\
\hline Blue-collar jobs & 20.6 & 28.1 & 28.1 & \\
\hline White-collar jobs & 24.9 & 32.6 & 39.3 & \\
\hline Others & 34.9 & 25.7 & 22.2 & \\
\hline Reads newspaper & & & & 0.861 \\
\hline Yes & 25.4 & 25.7 & 26.5 & \\
\hline No & 74.6 & 74.3 & 73.5 & \\
\hline Watches TV & & & & 0.075 \\
\hline Yes & 73.5 & 69 & 72.6 & \\
\hline No & 26.5 & 31 & 27.4 & \\
\hline Listens to radio & & & & 0.087 \\
\hline Yes & 5.8 & 10 & 10.8 & \\
\hline No & 94.2 & 90 & 89.2 & \\
\hline
\end{tabular}

${ }^{a}$ Significant at $p<0.05$. 
Table 3. Results of the binary logistic regression on the factors associated with non- and under-utilization of maternal healthcare services.

\begin{tabular}{|c|c|c|c|c|c|c|}
\hline & \multicolumn{3}{|c|}{ Non-utilization } & \multicolumn{3}{|c|}{ Underutilization } \\
\hline & $p$ & OR & $95 \% \mathrm{CI}$ & $p$ & OR & $95 \% \mathrm{CI}$ \\
\hline \multicolumn{7}{|l|}{ Residency } \\
\hline Rural & NS & 0.68 & $0.45-1.03$ & NS & 0.88 & $0.74-1.04$ \\
\hline Urban (Ref) & (Ref) & (Ref) & (Ref) & (Ref) & (Ref) & (Ref) \\
\hline \multicolumn{7}{|c|}{ Education level of the participant } \\
\hline Nil & $<0.001^{a}$ & 10.45 & $2.80-19.00$ & $0.004^{a}$ & 1.69 & $1.18-2.43$ \\
\hline Primary & $0.003^{a}$ & 6.80 & $2.88-14.62$ & $0.019^{a}$ & 1.43 & $1.06-1.94$ \\
\hline Secondary & NS & 3.05 & $1.88-7.60$ & NS & 1.00 & $0.78-1.29$ \\
\hline Higher (Ref) & (Ref) & (Ref) & (Ref) & (Ref) & (Ref) & (Ref) \\
\hline \multicolumn{7}{|c|}{ Education level of the husband } \\
\hline Nil & NS & 1.28 & $0.81-2.01$ & NS & 1.15 & $0.84-1.56$ \\
\hline Primary & NS & 0.67 & $0.43-1.03$ & NS & 1.00 & $0.76-1.31$ \\
\hline Secondary & NS & 1.31 & $0.84-2.03$ & NS & 0.95 & $0.75-1.20$ \\
\hline Higher (Ref) & (Ref) & (Ref) & (Ref) & (Ref) & $(\mathrm{Ref})$ & (Ref) \\
\hline \multicolumn{7}{|c|}{ Husband's occupation } \\
\hline Farming & NS & 1.18 & $0.92-1.52$ & NS & 1.18 & $0.92-1.52$ \\
\hline Blue-collar & NS & 0.97 & $0.79-1.18$ & NS & 0.97 & $0.79-1.18$ \\
\hline White-collar & NS & 0.96 & $0.78-1.19$ & NS & 0.96 & $0.78-1.19$ \\
\hline Others (Ref) & (Ref) & (Ref) & (Ref) & (Ref) & (Ref) & (Ref) \\
\hline \multicolumn{7}{|l|}{ Wealth index } \\
\hline Poorest & $<0.001^{a}$ & 9.28 & $3.60-23.90$ & NS & 1.00 & $0.69-1.45$ \\
\hline Poorer & $<0.001^{a}$ & 7.81 & $3.21-18.98$ & NS & 1.06 & $0.77-1.45$ \\
\hline Middle & $<0.001^{a}$ & 6.27 & $2.73-14.35$ & NS & 1.13 & $0.88-1.46$ \\
\hline Rich & $<0.001^{a}$ & 4.37 & $1.95-9.76$ & NS & 1.04 & $0.84-1.29$ \\
\hline Richest & (Ref) & (Ref) & (Ref) & (Ref) & (Ref) & (Ref) \\
\hline \multicolumn{7}{|c|}{ Microcredit borrower } \\
\hline Yes & NS & 1.02 & $0.71-1.45$ & NS & 0.93 & $0.78-1.11$ \\
\hline No & (Ref) & (Ref) & (Ref) & (Ref) & $(\operatorname{Ref})$ & (Ref) \\
\hline \multicolumn{7}{|l|}{ Food security level } \\
\hline Severely insecure & $0.001^{a}$ & 4.10 & $1.79-9.38$ & $0.040^{a}$ & 3.46 & $1.058-11.354$ \\
\hline Insecure & NS & 1.31 & $0.92-1.86$ & NS & 1.61 & $0.94-2.74$ \\
\hline Moderately secure & $0.017^{a}$ & 1.25 & $1.04-1.51$ & NS & 0.99 & $0.68-1.45$ \\
\hline Secure & (Ref) & (Ref) & (Ref) & (Ref) & (Ref) & (Ref) \\
\hline
\end{tabular}

Note: Reference category: Group 3. Ref, denotes the reference category; NS, not significant; OR, odds ratio.

${ }^{a}$ Significant at $p<0.05$. 
MHS utilization status. The findings of the study were well in line with the study hypothesis. In addition to the main findings, the study also revealed that the rate of MHS attendance in the sample population was quite low. A review of the literature suggests that a similar scenario exists in most other countries in South Asia (Moran et al. 2007; Singh et al. 2012), contributing to the remarkably high MMR among the impoverished population (Vora et al. 2009; Yaya et al. 2017).

HFI, as the explanatory variable of primary interest in this study, was found be significantly associated with MHS utilization status. Previous studies have demonstrated the link between chronic food vulnerability and the poor uptake of healthcare services (Kushel et al. 2001). Poor households usually have to spend the bulk of their income on food, and as a consequence face hard trade-offs between food and other competitive necessities such as education and healthcare (Bishwajit et al. 2014). Findings are similar even from studies in the USA where the expenditure on food as a percentage of total disposable income is one of the lowest among all countries (Kushel et al. 2001). A study following the food crisis of 2008 exploring households' coping strategies in Bangladesh found that the rise in food prices was associated with the decreased consumption of rice (a staple food in Bangladesh), increased student dropout at the high school level (with higher proportions for girls), and elevated levels of domestic violence, which all result in significantly adverse effects on the utilization of MHS (Raihan 2009). The Bangladesh Government has periodically launched many food security initiatives to safeguard the health and nutrition of its marginalized population. The findings of this study suggest that national food policy making targeting the promotion of food security among socioeconomically disadvantaged communities will substantially contribute to the increased utilization of MHS. Successful integration of social awareness programs targeting the sociocultural barriers to promoting maternal health and countrywide food security programs can prove highly rewarding. Nonetheless, mothers and female children were found to be deprived of food in households (Kushel et al. 2001; Baig-Ansari et al. 2006).

To our knowledge, there is no prior study exploring the association between MHS and HFI using nationally representative data. A strong point of this study is that we used data from the latest DHS survey performed in the country. Also of importance is the cluster sampling method of the study population, which means that sample participants were representative of the general population. However, using secondary data meant that authors had no control over the selection of variables, the quality of the data, and the measurement of the indicators. The rate of MHS utilization rate might have changed since the survey was conducted. Moreover, we did not control for geographic barriers to MHS, which has been shown to have influences on HSB.

\section{Conclusion and policy suggestions}

Women from food insecure households are less likely to receive MHS than their food secure counterparts. Household wealth status and individual educational level were also strongly correlated with the demand for MHS. The findings of this study bear important policy implications for designing reproductive healthcare services in Bangladesh. Health policies targeted at promoting maternal health and services utilization must emphasize improving food security and the economic empowerment of marginalized households, especially when there is a pregnant woman. Further studies should focus on the potential of food-security-based approaches to improve maternal health utilization in Bangladesh.

\section{Acknowledgements}

The authors wish to acknowledge the provision of the datasets by the DHS program. 


\section{Author contributions}

GB conceived and designed the study. GB performed the experiments/collected the data. GB and SY analyzed and interpreted the data. GB and SY contributed resources. GB and SY drafted or revised the manuscript.

\section{Competing interests}

The authors have declared that no competing interests exist.

\section{Data accessibility statement}

All relevant data are within the paper.

\section{References}

Adegoke A, Utz B, Msuya SE, and van den Broek N. 2012. Skilled birth attendants: who is who? A descriptive study of definitions and roles from nine Sub Saharan African countries. PLoS ONE, 7(7): e40220. PMID: 22808121 DOI: 10.1371/journal.pone.0040220

Baer TE, Scherer EA, Fleegler EW, and Hassan A. 2015. Food insecurity and the burden of health-related social problems in an urban youth population. Journal of Adolescent Health, 57(6): 601-607. PMID: 26592328 DOI: 10.1016/j.jadohealth.2015.08.013

Baig-Ansari N, Rahbar MH, Bhutta ZA, and Badruddin SH. 2006. Child's gender and household food insecurity are associated with stunting among young Pakistani children residing in urban squatter settlements. Food and Nutrition Bulletin, 27(2): 114-127. PMID: 16786978 DOI: 10.1177/ 156482650602700203

Bhargava V, and Lee JS. 2016. Food insecurity and health care utilization among older adults in the United States. Journal of Nutrition in Gerontology and Geriatrics, 35(3): 177-192. PMID: 27559853 DOI: $10.1080 / 21551197.2016 .1200334$

Bishwajit G. 2015. Nutrition transition in South Asia: the emergence of non-communicable chronic diseases. F1000Research, 4: 8. PMID: 26834976 DOI: 10.12688/f1000research.5732.2

Bishwajit G, Ide S, and Ghosh S. 2014. Social determinants of infectious diseases in South Asia. International Scholarly Research Notices, 2014: 135243. DOI: 10.1155/2014/135243

Cleland J, Bernstein S, Ezeh A, Faundes A, Glasier A, and Innis J. 2006. Family planning: the unfinished agenda. The Lancet, 368(9549): 1810-1827. PMID: 17113431 DOI: 10.1016/S0140-6736(06) 69480-4

Darmstadt GL, Bhutta ZA, Cousens S, Adam T, Walker N, and de Bernis L. 2005. Evidence-based, cost-effective interventions: how many newborn babies can we save? The Lancet, 365: 977-988. PMID: 15767001 DOI: 10.1016/S0140-6736(05)71088-6

Dowswell T, Carroli G, Duley L, Gates S, Gülmezoglu AM, Khan-Neelofur D, et al. 2010. Alternative versus standard packages of antenatal care for low-risk pregnancy. Cochrane Database of Systematic Reviews, (10): CD000934. PMID: 20927721 DOI: 10.1002/14651858.CD000934. pub2

Dynes M, Buffington ST, Carpenter M, Handley A, Kelley M, Tadesse L, et al. 2013. Strengthening maternal and newborn health in rural Ethiopia: early results from frontline health worker community 
maternal and newborn health training. Midwifery, 29: 251-259. PMID: 22342173 DOI: 10.1016/j. midw.2012.01.006

Finlayson K, and Downe S. 2013. Why do women not use antenatal services in low- and middleincome countries? A meta-synthesis of qualitative studies. PLoS Medicine, 10(1): e1001373. DOI: 10.1371 /journal.pmed.1001373

Hogan MC, Foreman K, Naghavi M, Ahn SY, Wang M, Makela SM, et al. 2010. Maternal mortality for 181 countries, 1980-2008: a systematic analysis of progress towards Millennium Development Goal 5. The Lancet, 375(9726): 1609-1623. PMID: 20382417 DOI: 10.1016/S0140-6736(10)60518-1

Kassebaum NJ, Bertozzi-Villa A, Coggeshall MS, Shackelford KA, Steiner C, Heuton KR, et al. 2014. Global, regional, and national levels and causes of maternal mortality during 1990-2013: a systematic analysis for the Global Burden of Disease Study 2013. The Lancet, 384: 980-1004. DOI: $10.1016 /$ S0140-6736(14)60696-6

Kushel MB, Vittinghoff E, and Haas JS. 2001. Factors associated with the health care utilization of homeless persons. JAMA, 285: 200-206. PMID: 11176814

Lewis G. 2003. Beyond the numbers: reviewing maternal deaths and complications to make pregnancy safer. British Medical Bulletin, 67(1): 27-37. PMID: 14711752

Moran AC, Winch PJ, Sultana N, Kalim N, Afzal KM, Koblinsky M, et al. 2007. Patterns of maternal care seeking behaviours in rural Bangladesh. Tropical Medicine \& International Health, 12(7): 823-832. PMID: 17596248 DOI: 10.1111/j.1365-3156.2007.01852.x

National Institute of Population Research and Training (NIPORT), Mitra and Associates, and ICF International. 2013. Bangladesh Demographic and Health Survey 2011. NIPORT, Mitra and Associates, and ICF International, Dhaka, Bangladesh and Calverton, Maryland [online]: Available from dhsprogram.com/pubs/pdf/FR265/FR265.pdf.

Nour NM. 2008. An introduction to maternal mortality. Reviews in Obstetrics \& Gynecology, 1(2): 77-81. PMID: 18769668

Raihan S. 2009. Impact of food price rise on school enrollment and dropout in the poor and vulnerable households in selected areas of Bangladesh. Bangladesh Economic Outlook, 2(1): 14.

Singh PK, Rai RK, Alagarajan M, and Singh L. 2012. Determinants of maternity care services utilization among married adolescents in rural India. PLoS ONE, 7: e31666. PMID: 22355386 DOI: 10.1371/ journal.pone.0031666

Sundari Ravindran TK. 2014. Poverty, food security and universal access to sexual and reproductive health services: a call for cross-movement advocacy against neoliberal globalisation. Reproductive Health Matters, 22(43): 14-27. PMID: 24908453 DOI: 10.1016/S0968-8080(14)43751-0

Swindale A, and Bilinsky P. 2006. Household dietary diversity score (HDDS) for measurement of household food access: indicator guide (v.2). FHI 360/FANTA, Washington, D.C. [online]: Available from fantaproject.org/sites/default/files/resources/HDDS_v2_Sep06_0.pdf.

Timmer CP. 2012. Behavioral dimensions of food security. Proceedings of the National Academy of Sciences of the United States of America, 109(31): 12315-12320. PMID: 20855628 DOI: 10.1073/ pnas.0913213107 
Vora KS, Mavalankar DV, Ramani KV, Upadhyaya M, Sharma B, Iyengar S, et al. 2009. Maternal health situation in India: a case study. Journal of Health, Population and Nutrition, 27(2): 184-201. PMID: 19489415

Winch PJ, Alam MA, Akther A, Afroz D, Ali NA, Ellis AA, et al. 2005. Local understandings of vulnerability and protection during the neonatal period in Sylhet district, Bangladesh: a qualitative study. The Lancet, 366(9484): 478-485. PMID: 16084256 DOI: 10.1016/S0140-6736(05)66836-5

Yaya S, Bishwajit G, and Ekholuenetale M. 2017. Factors associated with the utilization of institutional delivery services in Bangladesh. PLoS ONE, 12(2): e0171573. PMID: 28192478 DOI: 10.1371/journal. pone.0171573

Young S, Wheeler AC, McCoy SI, and Weiser SD. 2014. A review of the role of food insecurity in adherence to care and treatment among adult and pediatric populations living with HIV and AIDS. AIDS and Behavior, 18(Suppl. 5): 505-515. PMID: 23842717 DOI: 10.1007/s10461-013-0547-4

Zanconato G, Msolomba R, Guarenti L, and Franchi M. 2006. Antenatal care in developing countries: the need for a tailored model. Seminars in Fetal and Neonatal Medicine, 11(1): 15-20. PMID: 16364704 DOI: 10.1016/j.siny.2005.10.002 